\title{
Iridium-Catalyzed Synthesis of Substituted Piperazines
}

Gategory

Synthesis of

Heterocycles

Key words

amination

cyclization

iridium catalysis

piperazines

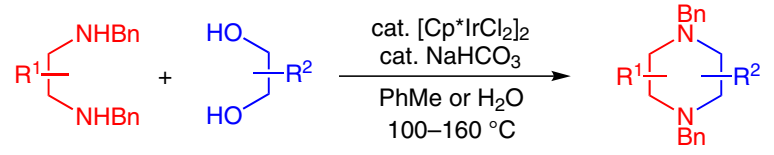

$\mathrm{R}^{1}=\mathrm{Me}, \mathrm{Ph} ; \mathrm{R}^{2}=\mathrm{Alk}, \mathrm{Ar}$

$>15$ examples; $35-100 \%$ yield

Selected examples:<smiles>c1ccc(C2NCCN[C@@H]2c2ccccc2)cc1</smiles><smiles>C1CC[C@H]2NCCN[C@H]2C1</smiles><smiles>CC1CNCCN1</smiles>

$94 \%$ yield<smiles>C[C@H]1CN[C@H]2CCCC[C@H]2N1</smiles>

$98 \%$ yield $(d r>20: 1)$

$69 \%$ yield<smiles>C[C@@H]1N[C@@H]2CCCC[C@H]2C[C@H]1C</smiles>

$81 \%$ yield $(\mathrm{dr}=3: 1)$

Piperazine preparation from two different diols:

$$
\begin{aligned}
& {\left[\mathrm{Cp}^{*} \mathrm{IrCl}_{2}\right]_{2}(1 \mathrm{~mol} \%)} \\
& \left.2 \mathrm{BnNH}_{2}+\right]_{\mathrm{HO}^{\prime}}^{\mathrm{HO}}
\end{aligned}
$$<smiles>Brc1ccccc1</smiles>

$90 \%$ yield
Significance: Reported is the preparation of substituted piperazines by an iridium-catalyzed alkylation of amines with vicinal diols. Using a catalyst system composed of $\left[\mathrm{Cp}^{*} \mid \mathrm{rCl} \mathrm{I}_{2}\right]_{2}$, either $\mathrm{NaHCO}_{3}$ or TFA as additives, and toluene or water as the solvent, a variety of piperazines with different substitution patterns are prepared by condensation of readily available primary alkylamines or 1,2-diamines with 1,2-diols. In order to achieve efficient cyclization, at least one substituent on either the diamine or diol is required. In most cases, mixtures of regioisomeric products are reported for those substrates possessing unsymmetrical substitution and, when a stereocenter is generated, the formation of the most stable isomer with equatorial substituent orientation is observed.

SYNFACTS Contributors: Victor Snieckus, Kevin D. Hesp (Pfizer) Synfacts 2013, 9(1), 0027 Published online: 17.12.2012 Dol: 10.1055/s-0032-1317873; Reg-No.: V15712SF
Comment: The development of efficient and modular methods for the preparation of substituted piperazine scaffolds has a significant impact in medicinal chemistry, as this motif is a commonly employed pharmacophore. This article describes a route for the preparation of these important frameworks, which proceeds through readily available 1,2-diamine and 1,2-diol starting materials. In general, piperazines were obtained in high yield (>70\%); however, the poor regioselectivity reported for unsymmetrical diol-diamine combinations suggests that more complicated piperazines will be difficult to access selectively by the current system. In addition, no comment was offered as to whether commonly encountered functional groups or other heterocycles were compatible with this catalyst system. 